\title{
Vertebrados consumidos por Brycon opalinus (Pisces, Characidae) em rios do Parque Estadual da Serra do Mar, SP
}

\author{
Leandro Muller Gomiero ${ }^{1,2}$, Denis Cristiano Briani ${ }^{1}$ \& Luís Olímpio Menta Giasson ${ }^{1}$
}

Biota Neotropica v6 (n3)-http://www.biotaneotropica.org.br/v6n3/pt/abstract?short-communication+bn00506032006

Recebido em 21/12/05.

Versão reformulada recebida em 26/02/2006

Publicado em 01/09/06

${ }^{1}$ Departamento de Zoologia, Instituto de Biociências, Universidade Estadual Paulista (UNESP), Av. 24-A, 1515, C. P. 199, CEP 13506-900, Rio Claro, São Paulo, Brasil.

2E-mail: leanmg@rc.unesp.br

\begin{abstract}
Gomiero, L.M.; Briani, D.C. and Giasson, L.O.M. Vertebrates consumed by Brycon opalinus (Pisces, Characidae) in rivers in State Park of the Serra do Mar (SP, Brazil). Biota Neotrop. Sep/Dec 2006 vol. 6, no. 3 http:// www.biotaneotropica.org.br/v6n3/pt/abstract?short-communication+bn00506032006 ISSN 1676-0603.
\end{abstract}

Analysis of feeding of the pirapitinga do sul, Brycon opalinus, an endangered fish in rivers of the Atlantic Forest of the Serra do Mar in southeastern Brazil, revealed the occurrence of uncommon items. Species of this genus are opportunist omnivores and feed on plant and animal items, such as flowers, leaves, fruits, seeds, and a wide variety of insects. In three rivers of State Park of the Serra do Mar - Santa Virgínia Unit, B. opalinus presented three uncommon animal items: the amphibians Hypsiboas aff. pardalis (Anura, Hylidae) and Eleutherodactylus guentheri (Anura, Leptodactylidae), and the mammal Oligoryzomys cf. nigripes (Rodentia, Sigmodontinae). This register was related with the rains, when animal or plant matter carried into the river can be consumed by B. opalinus, even if they are not habitually eaten by this species. The preserved riparian forest is of prime importance in supplying animal and plant food items and for maintaining biotic and abiotic conditions for the survival of B. opalinus.

Key words: Anura, Rodentia, pirapitinga do sul, Atlantic Forest, predation, preservation

\section{Resumo}

Gomiero, L.M.; Briani, D.C. and Giasson, L.O.M. Vertebrados consumidos por Brycon opalinus (Pisces, Characidae) em rios do Parque Estadual da Serra do Mar, SP. Biota Neotrop. Sep/Dec 2006 vol. 6, no. 3 http://www.biotaneotropica.org.br/ v6n3/pt/abstract?short-communication+bn00506032006 ISSN 1676-0603.

A análise da alimentação da pirapitinga do sul (Brycon opalinus), peixe ameaçado de extinção de rios da Mata Atlântica da Serra do Mar na região Sudeste, revelou a ocorrência de itens alimentares incomuns. As espécies deste gênero são onívoras oportunistas e alimentam-se de itens vegetais e animais, tais como: flores, folhas, frutos e sementes e grande variedade de insetos. Em três rios do Parque Estadual da Serra do Mar - Núcleo Santa Virgínia foram encontrados exemplares de B. opalinus que consumiram três itens animais incomuns, os anfíbios Hypsiboas aff. pardalis (Anura, Hylidae) e Eleutherodactylus guentheri (Anura, Leptodactylidae) e o mamífero Oligoryzomys cf. nigripes (Rodentia, Sigmodontinae). O registro do consumo destas espécies de vertebrados foi relacionado com o período de chuvas, quando o material animal ou vegetal carreado até o rio pode ser consumido por B. opalinus, mesmo que não sejam itens habituais para a espécie. A mata ripária preservada, como foi verificado nos três rios do Parque Estadual da Serra do Mar - Núcleo Santa Virgínia (SP), é de suma importância para o fornecimento de itens alimentares animais e vegetais e pela manutenção das condições bióticas e abióticas para a sobrevivência de B. opalinus.

Palavras-chave: Anura, Rodentia, pirapitinga do sul, Mata Atlântica, predação, preservação 


\section{Introdução}

O Estado de São Paulo detém a maior área de Mata Atlântica e ecossistemas costeiros associados do País, representando aproximadamente 7\% de sua cobertura vegetal original. O Núcleo Santa Virgínia é uma das unidades do Parque Estadual da Serra do Mar e apresenta atributos que o coloca como uma das principais áreas de conservação da Floresta Atlântica. O Núcleo está na bacia hidrográfica do rio Paraibuna e algumas espécies importantes e ameaçadas da fauna (Brasil 2003, 2004) são registradas nessa unidade, como o mono-carvoeiro Brachyteles arachnoides (Geoffroy 1806), a onça-pintada Panthera onca (Linnaeus 1758), a jacutinga Pipile jacutinga (Spix 1825), e, em especial, a pirapitinga do sul Brycon opalinus (Cuvier 1819), peixe dos rios de cabeceira da bacia do rio Paraíba do Sul (Villani 1998, Hilsdorf \& Petrere Jr. 2002). Esta bacia, localizada no norte da distribuição da Floresta Ombrófila Densa do Estado de São Paulo, de modo geral possui alta percentagem de espécies endêmicas de peixes. Isto se deve a combinações de características topográficas e fisionômicas que produzem ambientes distintos, o que favorece a ocorrência de um grande número de espécies, cada qual adaptada a um subconjunto particular destes ambientes, elevando o número de espécies endêmicas (Buckup 2003).

O gênero Brycon pertence à família Characidae e compreende pelo menos 38 espécies (Lima 2003), sendo um dos gêneros com mais espécies entre os Characiformes. As espécies de Brycon são tipicamente prateadas, de médio a grande porte e usualmente importantes para os pescadores comerciais e de subsistência. O gênero é distribuído do México à bacia do rio da Prata (Lima \& Castro 2000).

A alimentação destes peixes consiste principalmente de material vegetal (folhas, flores, frutos e sementes) e de material animal (insetos terrestres e às vezes peixes), esta dieta pode variar ontogeneticamente tornando-se cada vez mais herbívora com o crescimento dos peixes (Menezes 1969, Kramer 1978, Corrêa 1981, Britski et al. 1984, Burcham 1988, Lima \& Castro 2000, Figueiredo-Garutti et al. 2002, GarciaCarreño et al. 2002). Neste trabalho relatamos a ocorrência de três espécies de vertebrados consumidas por Brycon opalinus (Figura 1) coletados em três rios do Parque Estadual da Serra do Mar-Núcleo Santa Virgínia, Estado de São Paulo.

\section{Material e Métodos}

A área de estudo abrange três rios (Paraibuna, Ipiranga e Grande) da bacia do rio Paraibuna, dentro do Parque Estadual da Serra do Mar-Núcleo Santa Virgínia, Estado de São Paulo (23 entre $17^{\prime}$ e $24^{\prime}$ 'S; $45^{\circ}$ entre $3^{\prime}$ ' e $11^{\prime} \mathrm{O}$, com altitude média de $850 \mathrm{~m}$ ). Foram efetuadas coletas mensais de janeiro a dezembro de 2004 com duração de quatro dias, sendo realizada a pesca em diversos trechos de cada rio, com redes de espera simples (malhas de 15, 20, 25, 30, 35 e 40 mm, medidas entre nós adjacentes). Cada unidade de rede de malhagem específica mediu $10 \mathrm{~m}$ de comprimento e $1,5 \mathrm{~m}$ de altura, totalizando $60 \mathrm{~m}$. A padronização do esforço de pesca foi efetuada mantendose constante o tempo de utilização dos aparelhos de pesca em cada local de coleta. As redes de espera ficaram submersas do final da tarde de um dia até a manhã do dia seguinte, quando ocorria a despesca.

No laboratório, os peixes foram identificados a nível específico e tomados os dados de comprimento total (CT) em centímetros e do peso total em gramas, sendo então, efetuada a análise do conteúdo estomacal com o método de Freqüência de ocorrência (Fo), o qual é a porcentagem de estômagos que possuem determinado item, em relação ao número total de estômagos com conteúdo, através da fórmula: $\mathrm{Fo}=(\mathrm{Ni} / \mathrm{Nt}) .100$, onde Ni é o número de estômagos onde ocorreu o item i e Nt é o número total de estômagos com alimento (Hyslop 1980). Os exemplares foram depositados no Departamento de Zoologia da Universidade Estadual Paulista (UNESP) em Rio Claro, São Paulo.

\section{Resultados e Discussão}

Foram capturados 266 exemplares de B. opalinus (4 a 36 cm CT) nas 12 coletas de 2004, sendo que 256 estômagos foram analisados. De forma geral, esta espécie é onívora com predominância de insetos e frutos provenientes da mata ribeirinha (L.M. Gomiero, dados não publicados). Na coleta de abril, dos 47 exemplares de $B$. opalinus analisados três ingeriram itens animais incomuns (Fo = 1,17). Nesta ocasião ocorreu precipitação e vento durante a noite do primeiro dia, com o total pluviométrico de 35,4 mm e pico de $13 \mathrm{~mm} /$ hora às 19:00 horas.

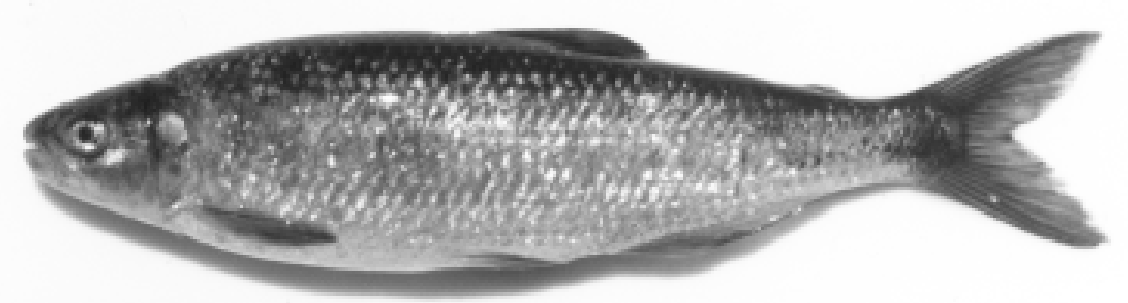

Figura 1. Exemplar de Brycon opalinus (pirapitinga do sul) capturado em rios do Parque Estadual da Serra do Mar-Núcleo Santa Virgínia (30 cm de comprimento total). Foto: Leandro M. Gomiero.

Figure 1. Specimen of Brycon opalinus (pirapitinga do sul) caught in rivers of State Park of the Serra do Mar-Santa Virginia Unit (total length: $30 \mathrm{~cm})$. Photograph by Leandro M. Gomiero. 
Um dos exemplares de B. opalinus ( $30 \mathrm{~cm}$ CT, $349 \mathrm{~g}$ ) foi capturado no rio Paraibuna e continha em seu estômago um indivíduo pouco digerido de Hypsiboas pardalis (Spix 1824) (Anura, Hylidae) (Figura 2) com aproximadamente 16,2 g. Este anuro, de tamanho médio entre $63 \mathrm{~mm}$ (machos) e $68 \mathrm{~mm}$ (fêmeas), possui dorso marrom com manchas escuras irregulares e membranas interdigitais e discos adesivos bastante desenvolvidos nas mãos e pés. Durante o período reprodutivo os machos vocalizam sobre o chão encharcado de brejos e poças, freqüentemente escondidos sob a vegetação. Em Boracéia, uma região de Floresta Atlântica no Sudeste do Brasil, foram encontrados, durante o dia, indivíduos inativos escondidos em frestas de um paredão rochoso e sob troncos e rochas em área pedregosa (Heyer et al. 1990).

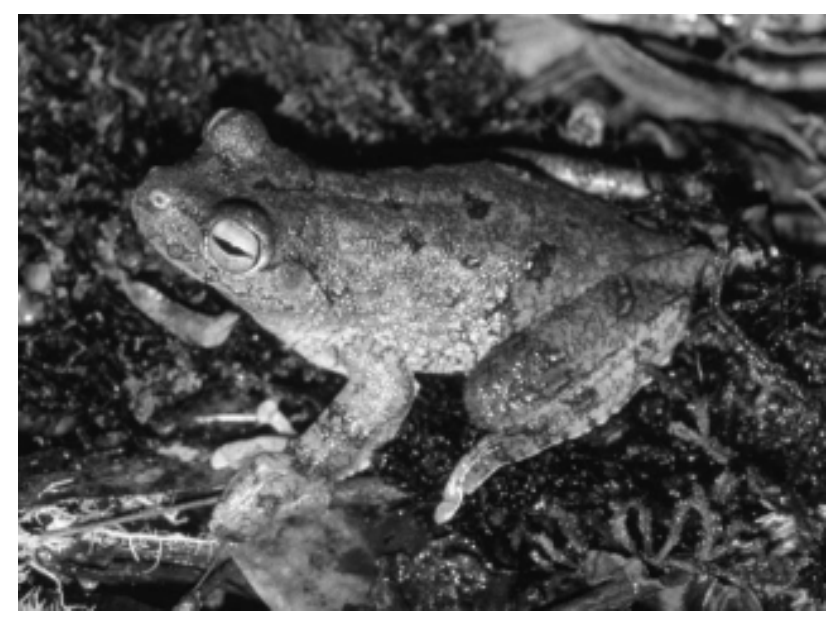

Figura 2. Hypsiboas pardalis no Parque Estadual da Serra do MarNúcleo Santa Virgínia $(6,2 \mathrm{~cm}$ de comprimento corporal). Foto: Luís O. M. Giasson.

Figure 2. Hypsiboas pardalis in State Park of the Serra do Mar-Santa Virginia Unit (body length: 6,2 cm). Photograph by Luís O. M. Giasson.

O segundo exemplar de B. opalinus (23,3 cm CT, 135 g) foi capturado no rio Ipiranga. Em seu estômago foi registrado um indivíduo de Eleutherodactylus guentheri (Steindachner 1864) (Leptodactylidae) (Figura 3). Este anuro, de tamanho médio entre $25 \mathrm{~mm}$ (machos) e $36 \mathrm{~mm}$ (fêmeas), possui coloração dorsal_bastante variável, com mesclas de tons creme, castanho e negro, que geram um padrão críptico com a serapilheira. Não possuem membranas interdigitais e possuem discos adesivos. Os machos vocalizam da serapilheira ou em poleiros baixos, onde ocorrem os acasalamentos, com maior intensidade sob chuva e no início da noite. Os indivíduos desta espécie são encontrados com freqüência próximos a córregos onde o solo se mantém mais úmido (Heyer et al. 1990).

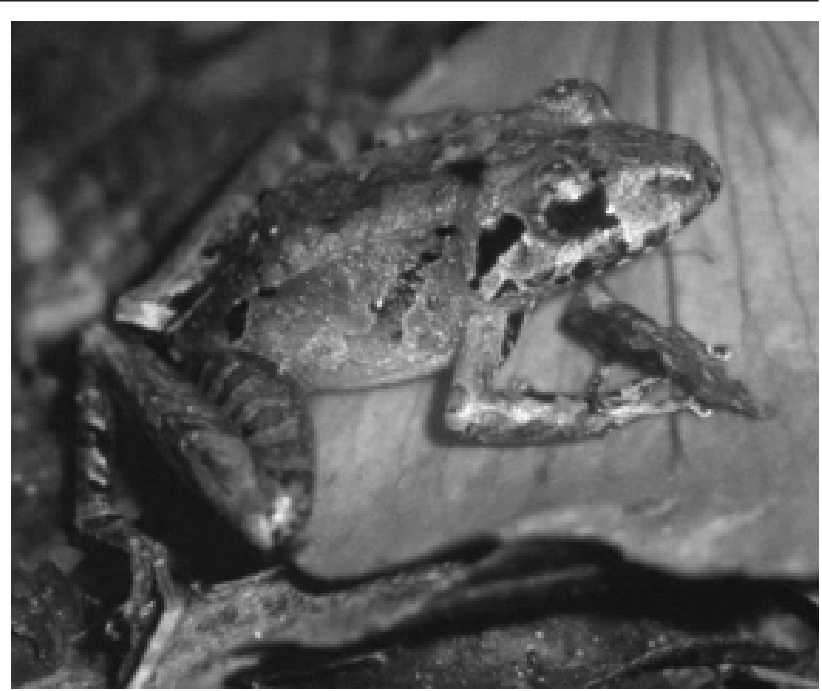

Figura 3. Eleutherodactylus guentheri no Parque Estadual da Serra do Mar-Núcleo Santa Virgínia (2,5 cm de comprimento corporal). Foto: Luís O. M. Giasson.

Figure 3. Eleutherodactylus guentheri in State Park of the Serra do Mar-Santa Virginia Unit (body length: 2,5 cm). Photograph by Luís O. M. Giasson.

O terceiro exemplar de B. opalinus (29,8 cm CT, 314 g) foi capturado no ribeirão Grande e continha em seu estômago um indivíduo de Oligoryzomys cf. nigripes (Olfers 1818) (Rodentia, Sigmodontinae) (Figura 4). De hábitos noturnos, é considerada uma espécie terrestre-escansorial (Stallings 1989). A massa corpórea dessa espécie varia de 9 a $40 \mathrm{~g}$ com o comprimento corporal de 70 a $110 \mathrm{~mm}$ e a cauda de 85 a 155 mm. Possui uma ampla distribuição pela América do Sul, com registros no Cerrado, Caatinga e Mata Atlântica (Stallings 1989, Olmos 1991). Habita áreas florestadas de crescimento primário e secundário, sendo uma das espécies de roedores mais abundantes no Núcleo Santa Virgínia (D.C. Briani, dados não publicados). Podem ser numerosos em áreas abertas como bordas de matas e margem de rios (Emmons \& Feer 1997).

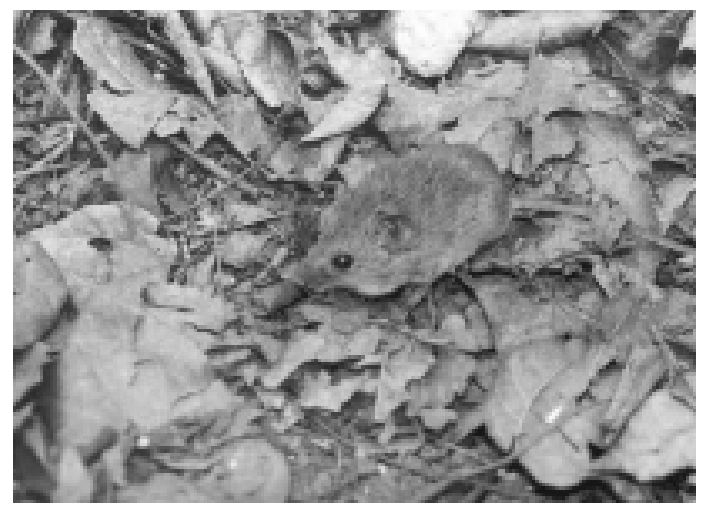

Figura 4. Oligoryzomys $c f$. nigripes no Parque Estadual da Serra do Mar-Núcleo Santa Virgínia (9 $\mathrm{cm}$ de comprimento corporal). Foto: Denis C. Briani.

Figure 4. Oligoryzomys cf. nigripes in State Park of the Serra do MarSanta Virginia Unit (body length: $9 \mathrm{~cm}$ ). Photograph by Denis C. Briani. 
Na Amazônia Central, o matrinxã Brycon cephalus (Günther 1869) é considerado onívoro, alimentando-se de sementes, frutos, flores, restos de vegetais e insetos, de acordo com a estação do ano e a disponibilidade destes alimentos. Insetos representaram um item importante nas cheias enquanto que flores foram mais freqüentes na seca, o que caracteriza essa espécie como oportunista (PizangoPaima et al. 2001). Também na Amazônia, a alimentação da jatuarana (Brycon sp.), além de frutos, sementes e insetos, consistiu de_uma pata de Isothrix sp. (Rodentia, Echimyidae), caracterizando-a como onívora e oportunista (Goulding 1980). No pantanal, a piraputanga Brycon microlepis (Perugia 1894) acompanha os bandos de macacos pregos, Cebus apella (Wied 1820), para ingerir os frutos, sementes e ocasionalmente insetos caídos da vegetação durante a atividade de alimentação dos macacos (Sabino \& Sazima 1999). É fato, portanto, a estreita relação das espécies de Brycon com a mata ribeirinha, sendo esta essencial para o pleno desenvolvimento e sobrevivência das populações selvagens.

Fica claro, que peixes deste gênero são oportunistas e têm atributos para a dieta onívora. Aárea de ocorrência de B. opalinus abrange riachos oligotróficos e a dependência dos itens alóctones provindos da mata ribeirinha é evidente (L.M. Gomiero, dados não publicados). Depois de chuvas intensas o material animal ou vegetal carreado até o rio pode ser consumido por esta espécie, mesmo que não sejam itens habituais, como foi registrado nos três rios do Parque Estadual da Serra do Mar-Núcleo Santa Virgínia.

A conservação de um determinado recurso biológico aquático exige o conhecimento de variáveis ecológicas, fisiológicas e comportamentais, importantes para definir como uma população sobrevive e se reproduz em diferentes ambientes (Hilsdorf \& Petrere Jr. 2002). Parte da solução para proteger uma espécie rara ou ameaçada, como $B$. opalinus, reside em entender sua relação biológica com o seu ambiente e a situação atual de suas populações.

\section{Agradecimentos}

À Fundação de Amparo à Pesquisa do Estado de São Paulo (processo no 03/05696-1) e ao Diretor do PESMNúcleo Santa Virgínia (J.P. Villani).

\section{Referências bibliográficas}

BRASIL, 2003. Instrução Normativa n³, de 27 de maio de 2003. Reconhece espécies da fauna brasileira ameaçadas de extinção. Ministério do Meio Ambiente, Brasília.

BRASIL, 2004. Instrução Normativa ${ }^{\circ} 5$, de 21 de maio de 2004. Reconhece espécies de invertebrados aquáticos e peixes ameaçados de extinção, sobreexplotadas ou ameaçadas de sobreexplotação. Ministério do Meio Ambiente, Brasília.
BRITSKI, H.A., SATO, Y. \& ROSA, A.B.S. 1984. Manual de identificação de peixes da região de Três Marias. CODEVASF, Brasília.

BUCKUP, P.A. 2003. Biodiversidade dos peixes da Mata Atlântica. Disponível em: <http://www.bdt.fat.org.br/ workshop/mata.atlantica/SE-S/peixes. Acessado em 18.mar.2003.

BURCHAM, J. 1988. Fish communities and environmental characteristics of two lowland streams in Costa Rica. Rev. Biol. Trop. 36(2A):273-285.

CORRÊA, V.L.S. 1981. Considerações sobre o hábito alimentar do Brycon devillei. An. Acad. Brasil. Ciênc. 53(3):630-631.

EMMONS, L.H. \& FEER, F. 1997. Neotropical rainforest mammals: a field guide. 2 ed. University of Chicago Press, Chicago.

FIGUEIREDO-GARUTTI, M.L., NAVARRO, I., CAPILLA, E., SOUZA, R.H.S., MORAES, G., GUTIERREZ, J. \& VICENTINI-PAULINOM, L.M. 2002. Metabolic changes in Brycon cephalus during post-feeding and fasting. Comp. Biochem. Physiol. Part A 132:467-476.

GARCIA-CARREÑO, F.L.,ALBUQUERQUE-CAVALCANTI, C., NAVARRETE DEL TORO, M.A. \& ZANIBONIFILHO, E. 2002. Digestive proteinases of Brycon orbignyanus: characteristics and effects of protein quality. Comp. Biochem. Physiol. Part B 132:343-352.

GOULDING, M. 1980. The fishes and the forest: explorations in Amazonian natural history. University of California Press, Los Angeles.

HEYER, W.R., RAND, A.S., CRUZ, C.A.G., PEIXOTO, O.L. \& NELSON, C.E. 1990. Frogs of Boracéia. Arq. Zool. S. Paulo 31(4):231-410.

HILSDORF, A.W.S. \& PETRERE JR., M. 2002. Conservação de peixes na bacia do rio Paraíba do Sul. Ciência Hoje 30(180):62-65.

HYSLOP, E.J. 1980. Stomach contents analysis: a review of methods and their application. J. Fish Biol. 17(4):411-429.

KRAMER, D.L. 1978. Reproductive seasonality in the fishes of a tropical stream. Ecology 59(5):976-985.

LIMA, F.C.T. 2003. Subfamily Bryconinae. In Checklist of the freshwater fishes of South and Central America (R.E. Reis, S.O. Kullander \& C.J. Ferraris Jr., orgs.). EDIPUCRS, Porto Alegre, p.174-181.

LIMA, F.C.T. \& CASTRO, R.M.C. 2000. Brycon vermelha, a new species of characid fish from the rio Mucuri, a coastal river of eastern Brazil. Ichthyol. Explor. Freshwaters 11(2):155-162.

MENEZES, N.A. 1969. The food of Brycon and three closely related genera of the tribe Acestrorhynchini. Pap. Av. Zool. 22:217-223. 
OLMOS, F. 1991. Observations on the behavior and population dynamics of some brazilian atlantic forest rodents. Mammalia 55(4):555-565.

PIZANGO-PAIMA, E.G, PEREIRA-FILHO, M. \&OLIVEIRAPEREIRA, M.I. 2001. Composição corporal e alimentar do matrinxã, Brycon cephalus, na Amazônia Central. Acta Amaz. 31(3):509-520.

SABINO, J. \& SAZIMA, I. 1999. Association between fruiteating fish and foraging monkeys in Western Brazil. Ichthyol. Explor. Freshwaters 10(4):309-312.

STALLINGS, J.R. 1989. Small mammal inventories in an eastern Brazilian Park. Bull. Florida State Mus. Biol. Sci. 34(4):153-200.

VILLANI, J.P. 1998. Plano de manejo das unidades de conservação: Parque Estadual da Serra do Mar-Núcleo Santa Virgínia. Plano de Gestão Ambiental-Fase 1. Secretaria do Meio Ambiente, São Paulo.

Título: Vertebrados consumidos por Brycon opalinus (Pisces, Characidae) em rios do Parque Estadual da Serra do Mar, SP.

Autores: Gomiero, L.M.; Briani, D.C. and Giasson, L.O.M.

Biota Neotropica, Vol. 6 ( número 3): 2006

http://www.biotaneotropica.org.br/v6n3/pt/ abstract?short-communication+bn00506032006

Recebido em 21/12/05 - Versão reformulada recebida em 26/02/2006 - Publicado em 01/09/06

ISSN 1676-0603 